\title{
Nutrigenetics and Nutrigenomics: Viewpoints on the Current Status and Applications in Nutrition Research and Practice
}

\author{
Michael Fenech ${ }^{a}$ Ahmed El-Sohemy ${ }^{b}$ Leah Cahill ${ }^{b}$ Lynnette R. Ferguson ${ }^{c}$ \\ Tapaeru-Ariki C. French ${ }^{c}$ E. Shyong Tai ${ }^{\mathrm{e}}$ John Milner ${ }^{\mathrm{d}}$ Woon-Puay Koh ${ }^{f}$ \\ Lin Xie $^{g}$ Michelle Zucker ${ }^{a}$ Michael Buckley ${ }^{a}$ Leah Cosgrove ${ }^{a}$ \\ Trevor Lockett ${ }^{\mathrm{a}}$ Kim Y.C. Fung ${ }^{\mathrm{a}}$ Richard Head ${ }^{\mathrm{a}}$ \\ ${ }^{a}$ CSIRO Preventative Health National Research Flagship, Adelaide, S.A., Australia; ${ }^{b}$ Department of

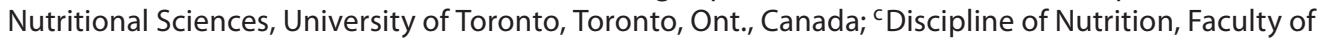 \\ Medical and Health Sciences, University of Auckland, and Nutrigenomics New Zealand, Auckland, \\ New Zealand; d Nutritional Science Research Group, Division of Cancer Prevention, National Cancer

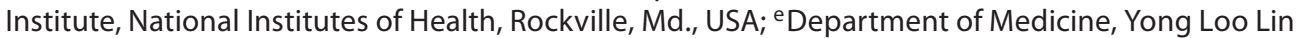 \\ School of Medicine, and f Department of Epidemiology and Public Health, National University of \\ Singapore, Singapore; ${ }^{9}$ Department of Nutrition and Food Hygiene, School of Public Health, \\ Jilin University, Changchun, People's Republic of China
}

\section{Key Words}

Dietetics $\cdot$ Nutrigenetics $\cdot$ Nutrigenomics $\cdot$ Nutrition Research $\cdot$ Personalised nutrition

\begin{abstract}
Nutrigenetics and nutrigenomics hold much promise for providing better nutritional advice to the public generally, genetic subgroups and individuals. Because nutrigenetics and nutrigenomics require a deep understanding of nutrition, genetics and biochemistry and ever new 'omic' technologies, it is often difficult, even for educated professionals, to appreciate their relevance to the practice of preventive approaches for optimising health, delaying onset of disease and diminishing its severity. This review discusses (i) the basic concepts, technical terms and technology involved in nutrigenetics and nutrigenomics; (ii) how this emerging knowledge can be applied to optimise health, prevent and treat diseases; (iii) how to read, understand and interpret nutrigenetic and nutrigenomic research results, and (iv) how this knowledge may potentially transform nutrition and dietetic practice, and the implications of such a transformation. This is in effect an up-to-date overview of the various aspects of nutrigenetics and nutrigenomics relevant to health practitioners who are seeking a better understanding of this new frontier in nutrition research and its potential application to dietetic practice.




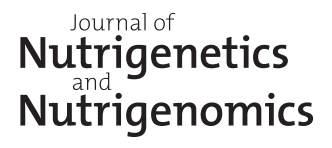

\begin{tabular}{l|l}
\hline J Nutrigenet Nutrigenomics 2011;4:69-89 \\
\hline $\begin{array}{l}\text { DOI: 10.1159/000327772 } \\
\text { Published online: May 28, } 2011\end{array}$ & ○ 2011 S. Karger AG, Basel \\
\hline Fenech et al.: Viewpoints on the Current Status of Nutrigenetics and Nutrigenomics
\end{tabular}

\section{Introduction}

A 1-day symposium titled 'Fundamentals of Nutrigenomics and Its Applications' was held in connection with the 19th International Congress of Nutrition in Bangkok on October 4, 2009. It was organised by the International Life Sciences Institute (South East Asia region) in collaboration with the Commonwealth Scientific and Industrial Research Organisation (Australia) with the aim of helping health professionals gain a good understanding and appreciation of the science of nutrigenetics and nutrigenomics as well as potential applications for improving health outcomes in genetic subgroups and individuals. This review is an update of the outcomes of the symposium and is intended to provide an overview of (i) the basic concepts, technical terms and technology involved in nutrigenetics and nutrigenomics; (ii) how this knowledge can be applied to optimise health, and prevent and treat diseases; (iii) how to read, understand and interpret nutrigenetic and nutrigenomic research, and (iv) how such knowledge may potentially transform nutrition and dietetic practice and the implications of such a transformation.

This review provides diverse viewpoints on the theory of nutrigenomics and nutrigenetics and the way that 'omic' technologies can be applied to interrogate nutrient-gene interactions and underlying mechanisms that may explain the genetic basis of interindividual differences in response to the same nutritional intakes. Various experimental approaches and interventional study designs are used in this field, and some of the typical examples and their results are discussed in the context of various aspects of health including the determination of dietary reference values for disease prevention, e.g. coeliac, neurodegenerative and cardiovascular diseases, obesity and cancer. It is evident, at this point in time, that despite the great promise of nutrigenetics and nutrigenomics, there is still a long way to go before dietary recommendations based on genetic testing either alone or in combination with gene expression, and metabolic and nutritional status biomarkers can make a substantial difference to current disease prevention and control practices.

\section{Overview of Nutrigenetics and Nutrigenomics}

Nutrigenetics and nutrigenomics are defined as the science of the effect of genetic variation on dietary response and the role of nutrients and bioactive food compounds in gene expression, respectively [1-6]. Exploitation of this genomic information along with high-throughout 'omic' technologies allows the acquisition of new knowledge aimed at obtaining a better understanding of nutrient-gene interactions depending on the genotype with the ultimate goal of developing personalised nutrition strategies for optimal health and disease prevention [1-6]. There are three central factors that underpin nutrigenetics and nutrigenomics as an important science. First there is great diversity in the inherited genome between ethnic groups and individuals which affects nutrient bioavailability and metabolism. Second, people differ greatly in their food/nutrient availability and choices depending on cultural, economical, geographical and taste perception differences. Third malnutrition (deficiency or excess) itself can affect gene expression and genome stability; the latter leading to mutations at the gene sequence or chromosomal level which may cause abnormal gene dosage and gene expression leading to adverse phenotypes during the various life stages.

Dietary reference values, e.g. recommended dietary allowance (RDA) or safe upper limits, which are designed for the general population and based on different metabolic outcomes, are not optimised for genetic subgroups which may differ critically in the activity of transport proteins for a micronutrient and/or enzymes that require that micronutrient as a 
cofactor. The ultimate goal is to (i) match the nutriome (i.e. nutrient intake combination) with the current genome status (i.e. inherited and acquired genome) so that genome maintenance, gene expression, metabolism and cell function can occur normally and in a homeostatically sustainable manner [1-7], and (ii) provide better interpretation of data from epidemiological and clinical intervention studies regarding health impacts of dietary factors that may help to revise recommendations for personalised nutrition $[6,8]$.

The fundamental hypotheses underpinning the science of nutrigenetics and nutrigenomics are the following:

- Nutrition may exert its impact on health outcomes by directly affecting expression of genes in critical metabolic pathways and/or indirectly by affecting the incidence of genetic mutation at the base sequence or chromosomal level which in turn causes alterations in gene dosage and gene expression.

- The health effects of nutrients and nutriomes (nutrient combinations) depend on inherited genetic variants that alter the uptake and metabolism of nutrients and/or the molecular interaction of enzymes with their nutrient cofactor and hence the activity of biochemical reactions.

- Better health outcomes can be achieved if nutritional requirements are customised for each individual taking into consideration both his/her inherited and acquired genetic characteristics depending on life stage, dietary preferences and health status.

It is important to note the difference between the terms nutrigenomics and nutrigenetics because although these terms are closely related they are not interchangeable. Nutrigenetics specifically investigates the modifying effects of inheritance (or acquired mutations in the case of cancer) in nutrition-related genes on micronutrient uptake and metabolism as well as dietary effects on health. We live in an era when it is becoming increasingly affordable to have one's genome determined providing information on a wide spectrum of critical mutations (e.g. single-nucleotide mutation, insertions-deletions, block substitutions, inversions or copy number variants) in critical genes involved in nutrient metabolism and pathways requiring micronutrients as cofactors [9]. Gender itself is a critical genetic variation that affects micronutrient requirements for health maintenance [10]. The key challenge is to determine whether it is possible to utilise this information meaningfully to provide reliable and predictable personalised dietary recommendations for specific health outcomes.

An important emerging aspect of nutrient-gene interaction studies with the potential for both intra- and transgenerational effects is epigenetics [11, 12]. Epigenetics refers to the processes that regulate how and when certain genes are turned on and off, while epigenomics pertains to analysis of epigenetic changes in a cell or entire organism. Epigenetic processes have a strong influence on normal growth and development, and this process is deregulated in diseases such as cancer. Diet on its own or by interaction with other environmental factors can cause epigenetic changes that may turn certain genes on or off. Epigenetic silencing of genes that would normally protect against a disease, as a result, could make people more susceptible to developing that disease later in life. The epigenome which is heritable and modifiable by diet is the global epigenetic pattern determined by global and gene-specific DNA methylation, histone modifications and chromatin-associated proteins which control expression of house-keeping genes and suppress the expression of parasitic DNA such as transposons.

DNA methylation occurs predominantly at $\mathrm{CpG}$ islands and in repetitive genomic sequence regions (e.g. LINE-1 sequences). It represses transcription directly by inhibiting the binding of specific transcription factors and indirectly by recruiting methyl-CpG binding proteins that remodel chromatin into an inactive state. Histones undergo post-translational modifications that alter their interaction with DNA and nuclear proteins. In particular the tails of histones $\mathrm{H} 3$ and $\mathrm{H} 4$ can be covalently modified at several residues by methylation, 
acetylation and phosphorylation. These modifications influence gene expression, DNA repair and chromosome condensation.

Lack of methylation due to deficiency of methyl donors (e.g. folate, vitamin $\mathrm{B}_{12}$, choline and methionine) or inhibition of DNA methyltransferases during life leads to transposon activation and promoter silencing when the activated transposons insert themselves adjacent to a house-keeping gene promoter [12-14]. As a consequence of these mishaps occurring stochastically, there is a relentless shift towards global DNA hypomethylation and tumour suppressor gene silencing with age, which leads to alterations in the genotype (due to chromosome malsegregation), gene expression profile, cellular phenotype and an increased risk of cancer $[12,14]$.

The field of nutrigenomics harnesses multiple disciplines and includes dietary effects on genome stability (DNA damage at the molecular and chromosome level), epigenome alterations (DNA methylation), RNA and micro-RNA expression (transcriptomics), protein expression (proteomics) and metabolite changes (metabolomics), all of which can be studied independently or in an integrated manner to diagnose health status and/or disease trajectory. However, of these biomarkers, only DNA damage is a clear biomarker of fundamental pathology that may be mitigated by promotion of apoptosis of genetically aberrant cells or by reducing the rate of DNA damage accumulation. Changes at the epigenome, transcriptome and proteome and metabolome levels may simply reflect modifiable homeostatic responses to altered nutritional exposure and on their own may not be sufficient to indicate definite irreversible pathology at the genome level.

DNA damage can be diagnosed in a number of complementary ways as follows: (i) damage to single bases (e.g. DNA adducts such as the addition of a hydroxyl radical to guanine caused by oxidative stress); (ii) abasic sites in the DNA sequence (measurable by use of the aldehyde-reactive probe); (iii) DNA strand breaks (commonly measured using the Comet assay); (iv) telomere shortening (measured by terminal restriction fragment length analysis, quantitative PCR or flow cytometry); (v) chromosome breakage or loss (usually measured using micronucleus cytome assays or metaphase chromosome analysis), and (vi) mitochondrial DNA damage (usually measured as deletions or base damage in the circular mitochondrial DNA sequence). These DNA damage biomarkers are currently at different levels of validation based on evidence relating to the association with nutrition (cross-sectional epidemiology and intervention studies) and disease (cross-sectional epidemiology and prospective cohort studies) [15]. The micronucleus assay in cytokinesis-blocked lymphocytes is currently the best validated biomarker for nutritional genomic studies of DNA damage. Given the advances in diagnostics technologies assessing DNA damage, it has now become feasible to (a) determine dietary reference values for DNA damage prevention and to start translating into practice the Genome Health Clinic concept of DNA damage prevention [14-16]. The latter is based on the recognition that damage to the genome is the most fundamental cause of developmental and degenerative diseases which can be accurately diagnosed and prevented by appropriate diet and lifestyle intervention at a genetic subgroup and personalised level.

\section{Experimental Approaches and Technologies Used in Studying Nutrigenetics and Nutrigenomics}

The ability of diet to affect the flow of genetic information can occur at multiple sites of regulation [17]. Advances in genomics, transcriptomics, proteomics and metabolomics have enabled a more rapid and comprehensive understanding of how bioactive compounds affect human health. Dietary bioactive compounds can be tested for their potential health-promoting properties by applying these different technologies to cell culture, and animal or human 
studies. Each experimental approach offers unique strengths and has certain limitations. As such, it is the combination of in vitro, animal, clinical and epidemiologic studies that are necessary to understand the role of specific nutrients and food bioactives in maintaining optimal human health. In human studies, the various 'omic' technologies need to be considered alongside data collected on nutritional, lifestyle, clinical, physiological, demographic and environmental factors. There is growing interest in understanding the role of gut microflora and the interactions that arise between the microbiome and host genome, which adds a further layer of complexity to the data being collected as well as how they are analysed. A systems biology approach with bioinformatics is usually needed to manage and interpret the large and complex datasets that can be generated [18]. The bioinformatic needs deal with the acquisition, management, storage, retrieval and analysis of such high-throughput datasets.

The biological effects of nutrients and food bioactives depend on a series of physiological processes, including absorption, transport, biotransformation, uptake, binding, storage and excretion, and cellular mechanisms of action, such as binding to nuclear receptors or regulating transcription factors. Each of these processes can involve several genes, each with common polymorphisms that could alter their function and ultimately the physiological response to a dietary compound. Research on diet-gene interactions has also explored how genes influence food preferences by affecting sensory, reward or energy homeostatic pathways [19]. Establishing a genetic basis for food likes or dislikes could lead to the development of novel food products targeted to specific genotypes or ethnic populations, and may explain some of the inconsistencies among studies relating foods to risk of chronic diseases [20].

Genetic variation across the human genome is being recognised as increasingly complex. Single nucleotide polymorphisms (SNPs) are the most common form of sequence variation in the human genome with $>10$ million SNPs reported in public databases [21], but copy number variants appear to be much more widespread than previously expected and might represent a greater source of genetic variation. Nucleotide repeats, insertions and deletions are other types of variations that could also modify an individual's response to diet. Genetic polymorphisms are normally found in at least $1 \%$ of the population, although common polymorphisms can occur in up to $40-50 \%$ of the population. Genetic polymorphisms may either have no consequence or have significant effects on the structure or function of the gene product. Different experimental approaches can be used to identify genetic variants that modify the effects of dietary factors or influence food preferences. A candidate gene approach is the most common method whereby a gene is selected based on its known or putative function. Depending on the number of SNPs in the gene, and whether any of them have known functional effects, analyses can be conducted using individual SNPs or combinations of SNPs, such as haplotypes. Recent studies have begun to apply genome-wide scans to identify previously unknown genetic variants that could modify response to diet. Understanding the genetic basis for individual variability in response to food bioactives will provide a more accurate measure of exposure of target tissues of interest to these compounds and their metabolites, and enable a greater understanding of the effects on human health and disease risk. Identifying relevant diet-gene interactions will not only benefit individuals seeking personalised dietary advice, but will also help improve public health recommendations by providing sound scientific evidence linking specific dietary compounds to various health outcomes.

A large number of studies have clearly shown that nutrients alter the expression of genetic information at the level of gene regulation, signal transduction and through alterations in chromatin structure and protein function. Diet can affect the expression levels of genes by acting on transcription factors or by causing epigenetic changes such as methylating DNA. Global changes in gene expression profiles could represent molecular 'signatures' that reflect exposure to specific nutrients [22]. Peripheral blood mononuclear cells can be used as a source of mRNA and serve as a surrogate for changes in target tissues of interest. Metabo- 


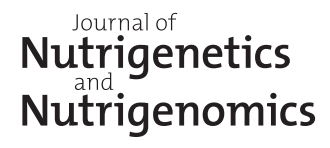

\begin{tabular}{l|l}
\hline J Nutrigenet Nutrigenomics 2011;4:69-89 \\
\hline $\begin{array}{l}\text { DOI: 10.1159/000327772 } \\
\text { Published online: May 28, } 2011\end{array}$ & $\odot 2011$ S. Karger AG, Basel \\
\hline Fenech et al.: Viewpoints on the Current Status of Nutrigenetics and Nutrigenomics
\end{tabular}

lomics and proteomics are increasingly being used to identify biomarkers of exposure and to distinguish between individuals with different dietary habits. The type of information generated could one day be incorporated into existing biobanks to relate diseases to possible nutritional exposures, when such information can no longer be collected or assessed reliably. There remains, however, a number of challenges related to sample handling and processing as well as data interpretation that need to be overcome [23].

Among the experimental study designs, epidemiologic studies are of particular interest because they examine the effects of a dietary exposure and genetic variants in humans. Limitations of nutritional epidemiologic studies include inaccuracies associated with estimating nutrient intakes. However, even if the precise intake levels were known, the biological 'dose' will vary greatly between individuals because of genetic variability affecting either the absorption, biotransformation, metabolism, distribution or elimination of a nutrient or food bioactive [24]. The incorporation of genetic polymorphisms into nutritional epidemiologic studies has helped to address several limitations inherent in such studies. These include recall bias among case-control studies and residual confounding among observational studies in general. One example of how nutrigenomics has been used to clarify the role of specific dietary factors comes from a study on coffee and heart disease [25]. Several studies had examined this association and concluded that coffee either increases risk, has no effect or decreases risk [17]. Although coffee is a rather complex beverage containing a large number of bioactive compounds, it is a major source of caffeine in several populations, and there have been concerns that caffeine might be particularly harmful to the cardiovascular system. Caffeinated-coffee was found to increase the risk of a heart attack among individuals who carry a version of a gene that makes them 'slow' caffeine metabolisers, but has no effect among individuals who are 'fast' caffeine metabolisers [26].

In addition to providing a more rational basis for giving personalised dietary advice, the knowledge gained by applying genomic information to nutrition research will also improve the quality of evidence used for making population-based dietary recommendations. Discoveries made in the field of nutrigenomics should translate into more effective dietary strategies to improve overall health by identifying unique targets for prevention. Several largescale international initiatives in nutrigenomics are currently underway with new programs being developed to address the gaps that exist and complement existing initiatives [27]. The sequencing of an individual's genome has fueled interest in the field of personalised medicine [28], but replicating and validating nutrigenetic studies need to remain a priority before personalised nutrition can be considered a worthwhile approach to improving human health.

\section{Nutrigenetics and Nutrigenomics in Optimising Well-Being and Performance}

Nutrition research has traditionally focused on the assumption that all individuals have the same nutritional requirements, although nutrionists do recognise differing needs of children as compared with adults, and of males as compared with females. Dietary guidelines in most countries have assumed a need to prevent deficiency diseases. These are typically presented as RDAs and state the amount of a nutrient that is needed per day for most people to stay healthy. The RDA is updated periodically to reflect new knowledge, but chronic diseases related to nutrition have shown a burgeoning increase in recent years.

A significant advance in nutritional understanding and tools that could be generally used in the establishment of individual dietary requirements was the development of the online 'Mypyramid' dietary tool [29]. This provides a limited recognition of differences between individuals. Thus, by entering age, sex, height, weight and level of physical activity, it is possible to get a personal eating plan. 


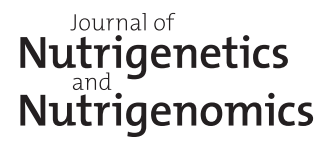

\begin{tabular}{l|l}
\hline J Nutrigenet Nutrigenomics 2011;4:69-89 \\
\hline DOI: 10.1159/000327772 \\
Published online: May 28, 2011 & ○ 2011 S. Karger AG, Basel \\
\hline Fenech et al.: Viewpoints on the Current Status of Nutrigenetics and Nutrigenomics
\end{tabular}

More recent years have seen advances in the era of nutrigenomics and nutrigenetics, whereby researchers investigated the effects of genes and gene variants on dietary requirements [30]. While animal models and systems biology approaches can be used to explore the interaction of these factors on gene pathways, extrapolation to humans and clinical implementation is not being widely used at present. However, it is increasingly becoming possible to bring an understanding of the genetic basis of health and disease to the achievable approach of personalised nutrition, using nutrigenetic approaches. Nutritional experts are learning to analyse information on genes and genetic variants, diet, lifestyle and environment, in order to develop nutritional strategies based on genetic makeup, typically but not exclusively in the form of SNPs and lifestyle.

The impetus for personalised nutrition strategies is also driven by an increasing scientific body of evidence documenting individual needs in relation to medical products both for prevention or treatment of disease [31]. Personalised pharma has had a slow route to market acceptance, but now shows significant potential. The field recognises the high number of people who die annually from adverse drug reactions [32, 33]. For a number of drugs, it is now recommended that variants in drug metabolism genes or other genes that affect individual response to the pharmaceutical are measured. The information thus gleaned can be applied to drug selection and/or dose optimisation, greatly affecting the efficiency and dose optimisation of an individual's treatment. Examples of areas in which this is being applied include variants affecting the efficacy of the well-known breast cancer drug, tamoxifen [34]. Nutrigenetics/nutrigenomics can potentially provide similar examples. The increasing quest for individualisation and/or optimisation in consumer goods, and willingness to pay a premium price, means that the marketplace may well be ready to accept personalised nutrition to prevent, manage or treat specific medical conditions.

Coeliac disease is one example for which personalised nutrition is currently being used. This debilitating disease results from an inability to tolerate gluten-containing foods in the diet. It leads to serious inflammatory symptoms, including changes in the colonic villi, that can only be significantly controlled by a strict dietary regime [35, 36]. That coeliac disease runs in families is well established, since twins have approximately a $75 \%$ concordance of disease development [37]. However, carrying the genes does not determine disease development per se, but only reveals a genetic predisposition to dietary factors. It appears that several genetic changes are involved, the most consistent of which are genetic variants in the HLA-DQ (DQ2 and/or DQ8) genes [38]. Such changes are necessary but not sufficient for the development of the disease. However, measurement of such changes indicates a high level of risk with a high degree of probability.

The only sustainable treatment for coeliac disease is a strict, lifelong gluten-free diet that avoids wheat, rye, barley and related products. For this purpose, a substantial range of glutenfree products is currently being successfully marketed. While genetic screening is not currently being used to identify these individuals, we predict that this will be a potential application.

Obesity is another disease with the potential for improved prevention using nutrigenetic knowledge. Arkadianos et al. [39] developed a personalised calorie-controlled diet, using 24 variants in 19 genes that were involved in metabolism to a weight reduction programme. These authors [39] compared weight loss and weight loss maintenance in 50 individuals who received exercise and dietary advice tailored to their genotype to optimise nutrient intake during weight loss and 43 control individuals who were given only generic diet and exercise advice. They were able to show that the group receiving personalised dietary advice not only performed better during the weight loss period, but also in weight loss retention over the following year.

In our own pilot study in Auckland, New Zealand, we investigated 5 variants (SNPs) in 4 genes in 68 participants, with 51 overweight-to-obese individuals (body mass index $>25$ 
$\mathrm{kg} / \mathrm{m}^{2}$ ) being compared with 17 control non-overweight individuals [40]. Similar to Arkadianos et al. [39], we constructed tailor-made personalised diets for the 51 individuals and followed results over 6 weeks. Furthermore, 1 of the 5 SNPs identified had a strong correlation with response to exercise $[41,42]$. Therefore, the 51 individuals were further subdivided into two groups: diet or combined diet and exercise intervention groups. Although a considerable number of practical issues arose from this part of the study, we had some success in stratifying individuals according to variants in 4 key genes, and tailoring diets according to their identified genetic requirements [40]. Our experience suggests that people are slow to take optimal health advice, especially if it requires increasing their commitment to exercise.

In an aging population, loss of cognition and neural control of motion becomes increasingly important. There is an emerging literature on the role of specific variants of genes involved in lipid metabolism which may accelerate the development of Alzheimer and Parkinson's disease [43]. For example, apolipoprotein E is the principal cholesterol carrier protein in the brain, and genetic variation in the gene encoding the variant apolipoprotein E4 is a significant risk factor for Alzheimer's disease whilst Parkinson's disease is partly caused by lipid peroxidation due to activation of phospholipases [43]. There is a strong need to develop preventive strategies for neurodegenerative diseases in those with genetic predisposition. However, despite promising results with dietary phytonutrient supplements in rodent models that are genetically susceptible to develop Alzheimer or Parkinson's disease [44-48], the knowledge base for humans is currently insufficient to make genotype-specific recommendations.

It is reasonable to assume that consumers are likely to be interested in knowing how to preserve their health and improving their well-being. Health is generally considered to be a continued state of soundness and vigor of body and mind. It is reflected in low infant mortality, longevity, and low morbidity to infectious and chronic diseases (i.e. increased disease resistance). The food industry is increasingly producing products to cater for people's specific nutritional and health needs. Whether these premium products may be of benefit to the 'worried well' (who may be financially capable of accessing them) as compared with individuals carrying a genetic susceptibility to a disease to whom the products may be targeted remains an unanswered question.

Bouwman [49] considered who would use such personalised nutrition products and associated advice and what are the limitations of providing potential users with highly specific information on individual health risks and benefits of specific eating habits. Her consumer survey work revealed the limited impact of personalised advice on eating practices to the present day, indicating that there is a significant mismatch of this approach with consumers' everyday life and habits. In general, she found that consumers primarily select food according to convenience, appearance, price, taste and social engagement. Health still appears to be relatively low on the average consumer's list of priorities.

\section{Nutrigenetics in Cardiovascular and Metabolic Disease Prevention and Control as Illustrated in an Ethnically Diverse Developed Country - The Case of Singapore}

The interindividual variability in the response to a diet is particularly evident in those countries which have large population segments of diverse ethnic backgrounds, and have undergone a rapid socio-economic development such as Singapore. Increase in life expectancy has given rise to an epidemiologic transition such that mortality from infection and malnutrition has largely been replaced by chronic non-communicable diseases, such as cardiovascular disease and cancer. Today, cancer and ischaemic heart disease represent the top 2 causes of death. The population of Singapore is heterogeneous, comprising three main ethnic groups (Chinese, Malays and Asian Indians). However, the various ethnic groups all live 


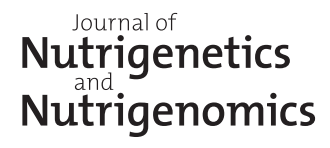

\begin{tabular}{l|l}
\hline J Nutrigenet Nutrigenomics 2011;4:69-89 \\
\hline DOI: 10.1159/000327772 \\
\begin{tabular}{l} 
Published online: May 28, 2011 \\
\hline Fenech et al.: Viewpoints on the Current Status of Nutrigenetics and Nutrigenomics
\end{tabular}
\end{tabular}

in integrated communities (mostly in public housing) in a country that is completely urbanised. This ethnic heterogeneity within a homogeneous environment offers interesting opportunities to examine the impact of ethnicity (and all that it comprises) on chronic disease during a rapid economic/epidemiologic transition [50].

It has become apparent that the epidemiologic transition has not affected all ethnic groups equally, particularly in relation to metabolic and cardiovascular diseases. As has been observed in several other populations, Asian Indians appear to be at high risk of cardiovascular disease. The rate of myocardial infarction in Asian Indians is threefold that of Chinese, with Malays intermediate between the other two ethnic groups [51]. The levels of cardiovascular risk factors also differ between ethnic groups [52, 53]. Obesity is most common amongst the Malays. However, the pattern of fat distribution is more peripheral. In contrast, Asian Indians have a larger waist circumference. This results in elevated insulin resistance, which is highest in Asian Indians, followed by Malays and Chinese. Asian Indians also exhibit a higher prevalence of diabetes mellitus and the lowest levels of high-density lipoprotein cholesterol compared to the Chinese, with Malays being intermediate between these ethnic groups. In contrast, Malays have the highest rates of hypertension.

Ethnicity is a construct that encompasses both genetic and cultural differences. Given that environmental factors play an important role in the pathogenesis of most of these chronic diseases, it seems unlikely that genetic differences per se underlie these ethnic differences. This is particularly so given that the changes in patterns of these diseases have occurred over several decades $[54,55]$ (a time frame that is unlikely to result in significant changes in the frequencies of genetic variants involving changes in the sequence within the genome). If indeed genetic variants are involved, it is more likely that genetic variants contribute to susceptibility to disease through modulating the effects of a modern urban environment on an individual's physiology.

To illustrate this, let us take a look at a common genetic variant at the FTO (fat mass- and obesity-associated gene), the rs9939609 SNP within the first intron of the gene. The presence of this genetic variant is associated with increased risk of obesity and type 2 diabetes in multiple populations $[56,57]$. As a follow up-to better understand the mechanisms by which this variant is associated with obesity, investigators studied food intake in children with and without the variant [58] and found that when faced with an unlimited supply of food, children with the variant associated with obesity consumed more calories. It was interesting to note that the greater energy consumption appeared to be more related to the energy density of the food rather than the weight of the food consumed. Several other studies have also noted that the effect of this variant is modulated by physical activity such that the effect of the variant is greater in those who are physically inactive $[59,60]$. Overall, this suggests that the presence of the FTO variant may connote susceptibility to obesity in an environment where food (particularly foods of high energy density) is readily available and low physical activity is common, which is precisely the environment that most urban settings provide.

To take this one step further, we have also examined the association between obesity and insulin resistance. It has been suggested that insulin resistance may be the mechanism that ties several cardiovascular risk factors, including obesity, dyslipidemia and hypertension together [61]. Obesity is highly correlated with insulin resistance and it has been suggested that overnutrition leading to obesity is a key factor behind the risk in metabolic and cardiovascular diseases seen in most countries as they undergo socio-economic development. However, it is evident that obesity does not fully explain the variation in insulin resistance in human populations. Body mass index only explains a small proportion of the variance in insulin resistance [62]. We have shown that insulin resistance (manifested as the presence of multiple features of the metabolic syndrome) can occur in the absence of obesity, and that despite the absence of obesity, it is still associated with an increased risk of cardiovascular 
disease. Previously, we have also shown that polymorphism at the PLIN locus (which encodes a protein that is important for the storage of lipids in adipose tissue) modulates the relationship between the intake of dietary saturated fat and insulin resistance, independently of obesity $[63,64]$.

Thus, it seems reasonable to hypothesise that different individuals can take different routes to obesity and insulin resistance. Some, like those with the FTO variants, may consume more energy-dense foods. Others, like those with PLIN polymorphisms, may develop insulin resistance as a consequence of increased dietary saturated fat intake. This also suggests that some individuals with insulin resistance or obesity will benefit more from one dietary intervention strategy than another. However, it is important to appreciate that these gene-nutrient interactions are highly complex, and that none of these hypotheses have been tested in interventional (as opposed to observational) studies. As such, there is a considerable amount of work that needs to be done before we will be in a position to initiate personalised dietary intervention based on genetic factors.

\section{Nutrigenetics/Nutrigenomics in Cancer Control and Management}

Concerns about rising global cancer rates, which are predicted to increase by about $50 \%$ by $2020[65,66]$, are intensifying discussions about appropriate prevention strategies. These projections point to a major preventable public health problem in both developing and developed countries. It remains to be determined if health care professionals are ready to deal with this major societal issue, including its economic impact.

Almost 35 years ago, Doll and Peto [67] suggested that diet likely accounted for about $30 \%$ of the risk of developing cancer. Since then, a wealth of evidence has pointed to the ability of multiple dietary components to modify cancer development and progression. The World Cancer Research Fund and American Institute of Cancer Research Report [65] concluded, on the basis of reviewing thousands of published articles, that diet contributes significantly to cancers worldwide, but that the actual percentage is highly dependent on the specific diet consumed and the type of cancer. Regardless, even this comprehensive evidence-based review points to the food relationship as 'probable' rather than 'compelling'. A quick glance at the scientific literature explains why this is the case. Reviews, which often extol the benefits of classes of foods or their components, also point to the considerable variation in response across experiments [68-70]. Some have argued that the interpretation of dietary data from large populations is filled with inaccuracies and is analogous to comparing apples and oranges. The inability to take into consideration individual variation in the amounts of foods/components consumed and how these are digested, metabolised to active intermediates and eliminated as waste products likely contributes significantly to the inability to unravel which foods are most important for health [71-74]. An integrated framework that simultaneously examines nutrigenomics, nutrigenetics, epigenetics and transcriptomics should provide important clues about who might benefit or be placed at risk due to dietary change [71-74]. It must be understood that this diet-phenotype relationship can also be influenced by the frequency and magnitude of insults that result from excess calories, viruses, bacteria and environmental contaminants $[72,73]$.

Genetic tests are already available for more than 1,700 diseases (http://www.ncbi.nlm. nih.gov/sites/GeneTests/). The availability of databases that will allow for the effective use of genomic information to create personalised intervention strategies is sorely needed. While pharmacogenetic testing has already emerged as a strategy for predicting the efficacy of drugs, a similar approach has not occurred with nutrigenetics. Pharmacogenetics is employing gene polymorphism information for predicting the extent to which drugs are transport- 


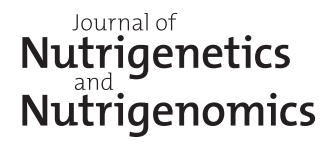

\begin{tabular}{l|l}
\hline J Nutrigenet Nutrigenomics 2011;4:69-89 \\
\hline DOI: 10.1159/000327772 \\
Published online: May 28, 2011 & ○ 2011 S. Karger AG, Basel \\
\hline Fenech et al.: Viewpoints on the Current Status of Nutrigenetics and Nutrigenomics
\end{tabular}

ed and metabolised, and thus for calculating the quantity needed to bring about a response. Similarly genetic variation in transport and metabolism of dietary factors may alter their impact on cancer. Moy et al. [74] suggest that knowledge about glutathione S-transferase M1 or T1 polymorphisms may be useful for predicting the amounts of isothiocyanates needed to reduce the risk of gastric cancer. In their study in men in Shanghai, those with the T1 null condition required a smaller amount of isothiocyanates to reduce risk than those with the non-null condition. Similarly, incorporating information about multiple $\mathrm{P}_{450}$ polymorphisms may help predicting those who would benefit most from limiting meat consumption in terms of colorectal cancer risk [75]. A subset of individuals, about 5\% of the population, had an increased risk, which was close to 50-fold higher compared with typical epidemiological findings suggesting a $20 \%$ risk, thus raising an intriguing question about whether or not current global public health announcements are the most appropriate when some, but not all, may be particularly vulnerable. A peroxisome proliferator-activated receptor $\delta$ polymorphism $(789 \mathrm{C} \rightarrow \mathrm{T})$ may also shed light on who might benefit most or be placed at risk due to exaggerated fish intake [76]. Unfortunately, while these studies reveal intriguing relationships among nutrigenetics, diet and cancer risk, they are largely unsubstantiated and thus remain largely speculative.

Copy number may be an additional variable that influences the response to foods. Some of the strongest evidence that this is the case comes from the observation that an increase in amylase gene copy number is associated with an increased enzymatic activity and starch digestion [77]. Some have proposed that copy number may account for about $25 \%$ individual variation in response [78].

Today, considerable focus is on genome-wide association studies (GWAS) as an approach for identifying genes that precipitate diseases, including cancer. Some GWAS are considering dietary variables [79], which is in contrast to the vast majority. At this point, GWAS have largely reconfirmed what was known, yet continue to point to the fact that it will not be an easy task to identify the most important genetic variables possibly because of redundant cellular controlled processes [80].

For nutrigenetics to have meaning, the genetic change must be intrinsically linked to a specific biological process $[72,73]$. Some of the strongest evidence for a link between a genetic polymorphism and a biological outcome comes from studies on the vitamin D receptor (VDR) gene Fok1 polymorphism and calcium homeostasis [81]. The longer VDR Fok1 $\mathrm{f}$ allele, which is less responsive to vitamin $\mathrm{D}$ than the shorter $\mathrm{F}$ allele, is linked to increased colorectal cancer risk when calcium intakes are low [82]. While the $\mathrm{f}$ allele is accompanied by a reduced calcium accretion and poorer bone health compared with the longer $\mathrm{F}$ allele, it remains to be determined how the change in calcium accretion relates to a change in cancer risk. Unquestionably, greater attention must be given to how a change in gene polymorphisms, deletions or copy number, for example, relate specifically to cancer processes and thereby changes in risk.

While considerable excitement exists for using nutrigenetics for predicting the benefits or risks of consuming specific foods, it is an area that remains in its infancy. A recent US government report found that nutrigenetic tests might be misleading or even harmful because they make claims that cannot be scientifically proven (http://www.gao.gov/new.items/ d06977t.pdf).

Considerable evidence suggests that epigenetic abnormalities induced by diet are also amongst the most important factors affecting cancer risk. At least four distinct processes are involved with epigenetics: DNA methylation, histone modifications, microRNAs as well as other noncoding regulatory RNA, and chromatin modelling [83]. Some of the strongest data linking diet to epigenetic events comes from studies with the agouti mouse model. Adding dietary factors (i.e. choline, betaine or folic acid), which enhance methylation, to the mater- 
nal diet of these pregnant mice leads to a change in the phenotype of some of the offspring [84]. Interestingly, adding genistein, which does not provide methyl groups, also leads to a change in the phenotype from a yellow to more agouti offspring [85]. Most importantly, these shifts in coat color are accompanied by a reduction in the risk of cancer as well as diabetes and obesity. The shift in obesity in these animals is noteworthy because of the worldwide obesity epidemic. Such findings should serve as justification for additional attention to bioenergetic-epigenetic interrelationships, especially those that are modified by dietary factors.

Myzak and Dashwood [86] have demonstrated that sulphoraphane, butyrate and allyl sulphur are effective inhibitors of histone deacetylase (HDAC). HDAC inhibition was associated with global increases in histone acetylation, enhanced interactions of acetylated histones with the promoter regions of the $P 21$ and $B A X$ genes, and elevated expression of p21Cip1/Waf1 and BAX proteins. Importantly, sulphoraphane has been reported to reduce HDAC activity in humans [87]. Future research likely needs to relate HDAC changes in humans to a change in a cancer-related process. Furthermore, since acetylation is only one method to regulate histone homeostasis [83], greater attention needs to be given to how nutrition might influence the other types of histone modifications.

Genomic and epigenomic processes likely do not entirely account for the ability of dietary factors to influence phenotypic changes since changes in the rate of transcription of genes (transcriptomics) can also be fundamental to cellular processes [88]. Multiple pathways appear to intersect as a cause of multiple diseases [89]. Thus, the examination of these pathways via transcriptomic profiles may simultaneously provide important clues about multiple disease risks. Noteworthy, several bioactive food components, including both essential and non-essential nutrients, can regulate gene expression patterns. Their influence on gene transcription and translation is not only concentration but also time dependent [90, 91]. Nevertheless, these changes may provide critical insights about the specificity of individual food components to influence one or more biological processes, including those involved in the risk of cancer development and/or tumour behaviour.

To date, few human studies have used transcriptomics to characterise the response to specific foods or their components. A recent study [92] suggested its potential by demonstrating specific gene expression patterns in leucocytes a few hours after consumption of a high-protein or -carbohydrate breakfast cereal. Thus, it is conceivable that a bolus approach might be used with selected foods or components in concert with a transcriptomic profile to generate a predictive model for those who might benefit or be placed at risk due to a change in eating behaviour. It is unclear if blood truly reflects changes in target tissues, and thus exfoliated or other more relevant cell types may be needed. In another recent study, prostate biopsies were effective in detecting transcriptomic shifts caused by consumption of a low-fat/ low-glycaemic-load diet compared with a traditional diet [93]. It should be noted that overinterpretation of the physiological significance of transcriptomic patterns is certainly possible since these are single snapshots. Furthermore, mRNA abundance is not always proportional to protein activity and thus may limit its overall utility to serve as a predictor of responders and non-responders.

\section{Application of 'Omic' Technologies in Nutritional Sciences to Understand Mechanisms of Action of Dietary Factors and Metabolites}

The role of 'omic' technologies such as transcriptomics (e.g. gene expression arrays) and proteomics in biological, clinical and nutritional sciences has expanded in recent years. These technologies are extensively used in an attempt to define molecular events involved in the health effects of dietary components or in nutrition-related diseases, such as inflamma- 
tory bowel disease, obesity, diabetes, cardiovascular disease or colorectal cancer [94]. These technologies provide the opportunity for global transcript and protein analyses, and bioinformatic analysis can be used to identify novel gene, protein and nutrient interactions or to uncover potentially novel mechanisms in disease progression. While the application of these technologies is becoming more accessible, the analysis of the complex large data sets that are generated presents multiple challenges. For example, the complexity of the analysis is underscored by the potential interaction of a chosen nutrient with the 30,000 genes in the human genome or the 100,000 different proteins believed to be translated. Integration of statistics and bioinformatics with biology is therefore essential for the analysis and interpretation of these datasets and requires the skills, expertise and knowledge of a multidisciplinary team. To illustrate how 'omic' technologies can provide a deeper understanding of potential molecular mechanisms underlying nutrigenomic effects, we describe the results from gene and protein expression (i.e. transcriptomic and proteomic) studies in colorectal cancer cell lines investigating the impact of butyrate, a metabolite generated in the colon by bacterial fermentation of dietary fibre or resistant starch $[95,96]$.

There is growing evidence to indicate that dietary fibre, in particular digestion-resistant starch, promotes bowel health, and one of the areas of focus for experimental research is its potential protection against the development of colorectal cancer [97]. Additional studies have shown that butyrate, one of the predominant short-chain fatty acids produced from the fermentation of resistant starch by the gut bacteria, may be responsible for its physiological effects [98]. While the cellular effects of butyrate are well documented, numerous studies have been conducted in order to elucidate the mechanisms by which butyrate may elicit its anti-tumorigenic effects. We have employed gene expression and proteomic analysis with colorectal cancer cell lines to understand the mechanism of action of butyrate with a particular focus on its apoptotic effects.

In colorectal cancer cell lines, we have shown that butyrate treatment induces apoptosis and inhibits proliferation after $48 \mathrm{~h}$ (fig. 1). Following this, proteomics and gene expression arrays were used to identify the mechanisms underlying butyrate-induced apoptosis using HT29 cells as the model system. Statistical and bioinformatic analyses were then employed to identify potentially important genes and proteins involved in the induction of apoptosis in colorectal cancer cells. Using proteomics (2D-DIGE and mass spectrometry), we were able to detect 1,347 proteins, including protein isoforms and modifications, and identified 139 proteins which are potentially involved in the apoptotic response to butyrate [99]. We further determined that butyrate affects these cellular functions:

- remodelling of the actin cytoskeleton;

- increased expression of oncogenic proteins;

- enhanced cell stress response;

- negative regulation of protein biosynthesis;

- negative regulation of cell growth, and

- inhibition of the glycolytic pathway (Warburg effect).

Parallel gene expression analysis in the HT29 cells using Affymetrix arrays was performed to identify genes influenced by butyrate. After $48 \mathrm{~h}$, statistical analysis identified 2,550 genes as being modulated by butyrate, representing approximately $10 \%$ of the human genome. These genes were found to be involved in biological processes such as DNA repair and transcription, cell cycle progression, cell metabolism and signal transduction. A poor correlation between gene (mRNA transcript) and protein expression was also found (fig. 2), further highlighting the complexity of the molecular interactions and the need to integrate statistical analysis with biology to extract appropriate hypotheses and conclusions.

These data can be used to determine the action of butyrate in the cell and to then correlate this with physiological measurements or outcomes. Recently, a small number of butyrate trans- 


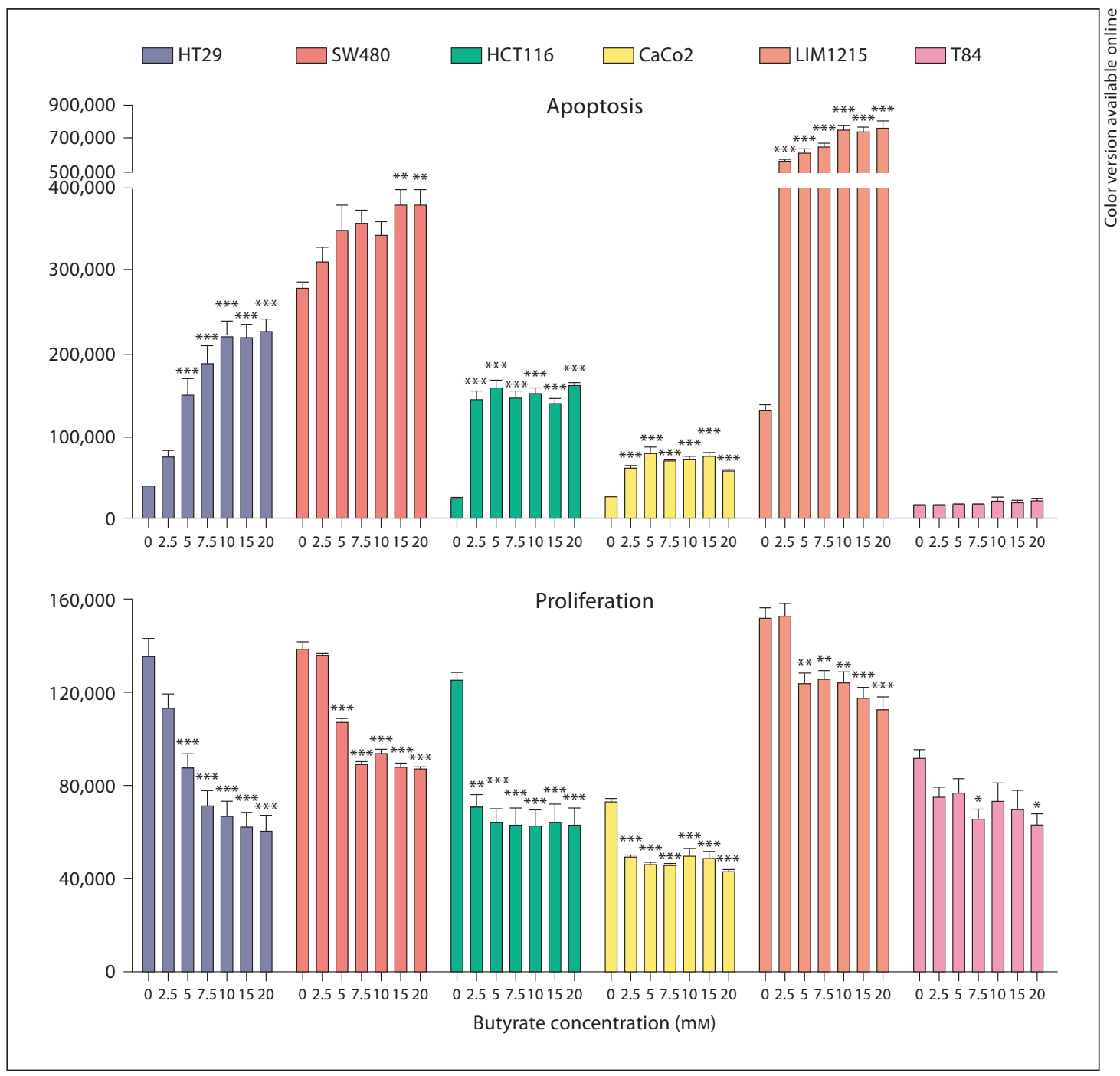

Fig. 1. Apoptosis and proliferation in colorectal cancer cell lines in response to butyrate [95]. Colorectal cancer cell lines (HT29, SW480, HCT116, Caco2, Lim1215 and T84) were treated with increasing concentrations of butyrate for $48 \mathrm{~h}$. In all cases, butyrate was found to induce apoptosis and inhibit the proliferation of cells, with the exception of the T84 cell line. In the T84 cell line, butyrate induced minimal/no apoptosis and had minimal effect on proliferation. ${ }^{*} \mathrm{p}<0.05,{ }^{* *} \mathrm{p}<0.01,{ }^{* *} \mathrm{p}<0.001$ compared to untreated cells using ANOVA with Tukey's post hoc test. Colorectal cancer cell lines (HT29, SW480, HCT116, CaCo2, Lim1215 and T84) were obtained from American Type Culture Collection (Manassas, Va., USA). Apoptosis and proliferation was measured following exposure to butyrate for $48 \mathrm{~h}$ according to methods described previously $[95,96]$. Statistical analysis was performed using the Prism v4.0 software package.

porters and receptors has been identified, including SLC5A8, GPR109, GPR56 and the GPR40 family of receptors, which includes GPR41 and GPR43 [100-102]. Although there are reports on the involvement of some of these receptors in the immune and inflammatory response as well as colorectal cancer [103-107], little is known about the intracellular mechanisms underlying these responses. Mining of 'omic' data, such as the proteomics and gene expression data that we have generated, may provide an insight into these mechanisms. Hypotheses that are generated may then be validated experimentally using PCR and protein-based assays. 


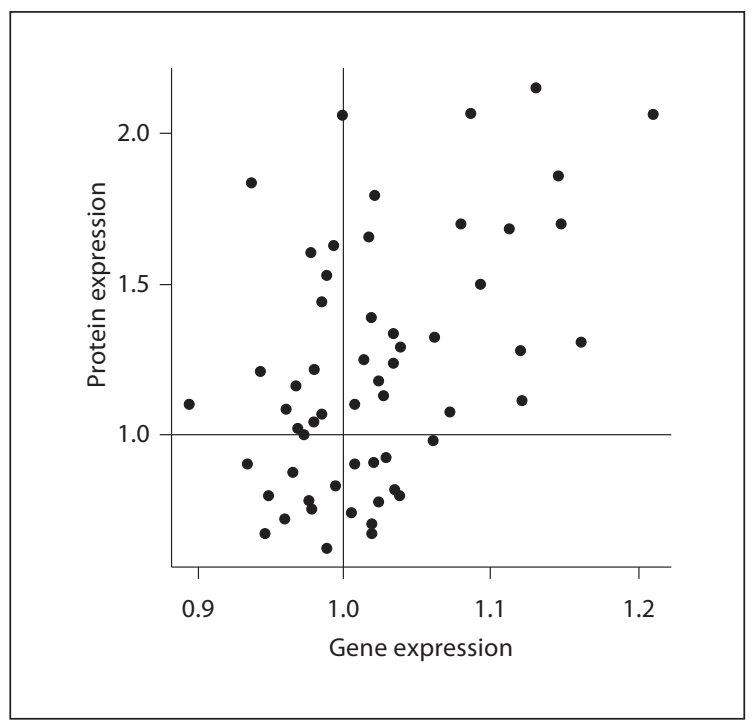

Fig. 2. Correlation between gene and protein expression when HT29 cells were treated with butyrate for $48 \mathrm{~h}$. After 48-hour butyrate treatment, 139 proteins were found to be differentially expressed. A direct comparison between the gene (mRNA transcript) and protein expression of these 139 proteins yielded a correlation of 0.48 ( $\mathrm{p}=0.00016$ ). Proteomic data were collected and analysed as described [95, 96]. Gene expression analysis was performed using Affymetrix arrays (Human Exon 1.0ST arrays) according to manufacturer's protocol (Affymetrix, Santa Clara, Calif., USA). Correlation analysis between protein and transcript expression was performed using the R statistical package.

We have highlighted the use of 'omic' technologies in the nutritional sciences, using butyrate as an example. These technologies together with appropriate bioinformatic and statistical tools can be applied to gain a deep understanding of the mechanisms by which any nutrient may exert its effects on the genome depending on the genetic background.

\section{Evaluation of Evidence from Nutrigenetic Case Studies}

There is an emerging need to carefully evaluate published papers on nutrient-genotype interactions with respect to whether the results are of sufficiently strong clinical relevance that they could be used to guide dietetic practice and recommendations to consumers.

Four well-conducted studies that have identified significant nutrient-gene interactions relating to nutrient bioavailability and health effects that are also backed by a credible biological model are considered and discussed briefly below [108-111]. The findings of two of these studies emphasise the importance of obtaining the RDA of a micronutrient in order to decrease the prevalence of deficiency and highlight that this may be particularly so in individuals who for genetic reasons are more susceptible to such deficiency. For example, one study concluded that obtaining the RDA for vitamin $\mathrm{C}$ is of particular importance for individuals with one or both null GSTM1/GSTT1 genotypes because in these cases inadequate dietary intake of vitamin $\mathrm{C}$ is more likely to result in serum ascorbic acid deficiency [108]. Another study showed that the genotype for the FADS1/FADS2 genes is an important modifier of the n-6 and n-3 fatty acid status during pregnancy, and suggests that minor allele variants of a common SNP in FADS2/FADS1 are more likely to accumulate 18:2n-6 fatty acids [109]. A nested case-control study within the Singapore Chinese Health Study Cohort 
showed a significant interaction between the level of green tea drinking and the activity of the angiotensin-converting enzyme (ACE) with respect to breast cancer risk depending on $A C E$ gene polymorphism [110]. Yet another study showed a significant association between mushroom intolerance and Crohn's disease in those carrying the T allele of the OCTN1 $(\mathrm{c} .1672 \mathrm{C} \rightarrow \mathrm{T})$ sodium-dependent organic cation transporter gene [111].

Although all of these studies show the plausibility of nutrient-gene interactions in diverse aspects of the nutritional status and potential health outcomes, it is evident that the new knowledge that was generated and the strength of association of outcomes with genotype was not strong enough to be used in clinical practice for personalised dietary recommendations. Also, there is as yet inadequate evidence to suggest that observed nutrient-genotype interactions observed within one ethnic group would also apply to any other ethnic group. There is a general concern at present as to whether studies examining the use of genetic test information in relation to diet are actually likely to change human behaviour [112]. Factors that are likely to limit uptake in dietetic practice include methodological weakness of experimental designs to assess effectiveness and health literacy of the people likely to be receiving the advice. Furthermore, medical practitioners and dieticians need to be properly trained to evaluate the relevance and suitability of specific nutrient-gene interaction studies for use in personalised nutrition advice. There is a considerable way to go before information such as the present can be used meaningfully by appropriately trained health professionals to modify disease risk or affect disease progression in a truly predictable, reproducible and verifiable manner.

The clinical usefulness of gene expression measurements in making personalised dietary recommendations has not yet been demonstrated. Furthermore, changes in gene expression may simply be a homeostatic adaptive response to changes in dietary patterns or associated life-style factors (e.g. exercise). Gene expression patterns may only become useful in clinical practice when patterns in an easily accessible sample (e.g. blood or buccal cells) that clearly and unequivocally identify a health or disease trajectory are properly validated. For these reasons, we did not consider gene expression studies in the case study section.

\section{Future of Nutrigenetics and Nutrigenomics and Implications for Nutritional Recommendations and Dietetic Practice}

It is becoming increasingly evident that nutrigenetics and nutrigenomics are taking a central stage in the investigation of the effect of nutrition on health outcomes, and that impacts of nutrients can be evaluated comprehensively by a multitude of 'omic' technologies and biomarkers. Some of these technologies are still in their infancy whilst others are much more mature and therefore differ significantly in their validation status with respect to health outcomes. That genetic background, gender and life stage can have an impact on nutritional requirements is becoming increasingly evident; however, translation of this knowledge into recommendations based on genotype or at the individual level is only practical in those few cases (e.g. phenylketonuria or galactosemia) when the effect of genotype clearly overwhelms the impact of any other factor and is the ultimate determining factor of the nutritional and health status for an individual or genetic subgroup. Nutrigenetic and nutrigenomic research is providing us with an avalanche of new knowledge and it will become increasingly evident which genetic factors need to be given particular attention when formulating recommendations for important genetic subgroups that have a significant prevalence in the population. Because responses between individuals to dietary changes, even within genetic subgroups, may differ considerably, it will be necessary to combine nutrigenetic-based advice with 'omic' biomarkers to test whether the personalised recommenda- 


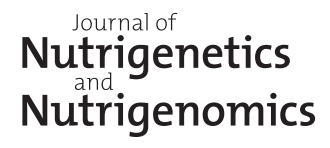

\begin{tabular}{l|l}
\hline J Nutrigenet Nutrigenomics 2011;4:69-89 \\
\hline $\begin{array}{l}\text { DOI: 10.1159/000327772 } \\
\text { Published online: May 28, 2011 }\end{array}$ & $\odot 2011$ S. Karger AG, Basel \\
\hline Fenech et al.: Viewpoints on the Current Status of Nutrigenetics and Nutrigenomics
\end{tabular}

tion given actually produces the expected nutritional change and health benefit within the individual. This repeating validation process is critical for success in the future. The evidence-based approach is the only mechanism that can ensure that the knowledge generated by nutrigenetic/nutrigenomic science is properly implemented and scrutinised. Furthermore, as nutrition becomes increasingly integrated with preventive medicine, it is essential that dieticians and medical practitioners as well as geneticists are properly educated in the field of nutrigenetics/nutrigenomics so that their principles and practice are properly utilised and not abused.

It is not only naïve, but also likely dangerous, to assume all individuals will respond identically to the foods they consume. The development of a personalising approach to nutrition for disease prevention and therapy will require a much more comprehensive understanding of nutrient-gene interactions and their impact on phenotype in order to identify, evaluate, and prioritise appropriately targeted strategies for dietary intervention. While the challenges associated with unravelling the nutrigenomic-disease inter-relationship will not be easy, the public health implications are enormous.

It is important to consider whether public health will be improved with individualised tailored recommendations. How costly will personalised nutrition and counseling be? Will people be motivated to adhere to a tailored diet? Will this approach be a luxury for those with money and education? There are inherent risks in utilising nutrigenetics/nutrigenomics in providing public health advice. These include fostering a simplistic view of the role of genes in health, and diluting general healthy eating messages. At the moment, there is a degree of public confusion and an immunity to messages that foster unpopular advice, such as 'get more exercise' or 'eat less calories'. Nevertheless, in the long term, these fields of endeavour may be the only way to optimise nutrition for optimal effects on health, wellness, and a slowing of the deterioration associated with the aging process.

\section{Acknowledgements}

Boon Yee Yeong and Mia Isabelle (both from ILSI South East Asia) are acknowledged for organising the symposium 'Fundamentals of Nutrigenetics/Nutrigenomics and Its Applications' in 2009, which led to the writing of this review. Nutrigenomics New Zealand is a collaboration between AgResearch Ltd., Crop \& Food Research, HortResearch and the University of Auckland, with funding through the Foundation for Research Science and Technology.

\section{References}

1 Simopoulos AP: Nutrigenetics/nutrigenomics. Annu Rev Public Health 2010;31:53-68.

2 Corella D, Ordovas JM: Nutrigenomics in cardiovascular medicine. Circ Cardiovasc Genet 2009;2:637-651.

-3 Trujillo E, Davis C, Milner J: Nutrigenomics, proteomics, metabolomics, and the practice of dietetics. J Am Diet Assoc 2006; 106:403-413.

4 Ferguson LR: Nutrigenomics approaches to functional foods. J Am Diet Assoc 2009;109:452-458.

5 Kaput J: Nutrigenomics research for personalized nutrition and medicine. Curr Opin Biotechnol 2008;19:110-120.

-6 Ordovas JM, Corella D: Nutritional genomics. Annu Rev Genomics Hum Genet 2004;5:71-118.

7 Fenech MF: Nutriomes and nutrient arrays - the key to personalised nutrition for DNA damage prevention and cancer growth control. Genome Integr 2010;1:11.

8 Simopoulos AP, Ordovas JM: Nutrigenetics and Nutrigenomics. World Review of Nutrition and Dietetics. Basel, Karger, 2004, vol 93.

-9 Frazer KA, Murray SS, Schork NJ, Topol EJ: Human genetic variation and its contribution to complex traits. Nat Rev Genet 2009;10:241-251.

10 Ordovas JM: Gender, a significant factor in the cross talk between genes, environment, and health. Gend Med 2007; 4(suppl B):S111-S122.

11 Jirtle RL, Skinner MK: Environmental epigenomics and disease susceptibility. Nat Rev Genet 2007;8:253-262. 


\section{Nutrigenetics \\ Nutrigenomics}

J Nutrigenet Nutrigenomics 2011;4:69-89

DOI: $10.1159 / 000327772$

Published online: May 28, 2011

2011 S. Karger AG, Base

Fenech et al.: Viewpoints on the Current Status of Nutrigenetics and Nutrigenomics
$>12$

Sharma S, Kelly TK, Jones PA: Epigenetics in cancer. Carcinogenesis 2010;31:27-36.

Aravin AA, Hannon GJ: Small RNA silencing pathways in germ and stem cells. Cold Spring Harb Symp Quant Biol 2008; 73:283-290.

Fenech M: The Genome Health Clinic and Genome Health Nutrigenomics concepts: diagnosis and nutritional treatment of genome and epigenome damage on an individual basis. Mutagenesis 2005;20:255-269.

Fenech MF: Dietary reference values of individual micronutrients and nutriomes for genome damage prevention: current status and a road map to the future. Am J Clin Nutr 2010;91:1438S-1454S.

Bull C, Fenech M: Genome-health nutrigenomics and nutrigenetics: nutritional requirements or 'nutriomes' for chromosomal stability and telomere maintenance at the individual level. Proc Nutr Soc 2008;67:146-156.

Ordovas JM, Corella D: Nutritional genomics. Annu Rev Genomics Hum Genet 2004;5:71-118.

de Graaf AA, Freidig A, De Roos B, et al: Nutritional systems biology modeling: from molecular mechanisms to physiology. PLoS Comput Biol 2009;5:e1000554.

Garcia-Bailo B, Toguri C, Eny KM, El-Sohemy A: Genetic variation in taste and its influence on food selection. OMICS 2009;13:69-80.

El-Sohemy A, Stewart L, Khataan N, et al: Nutrigenomics of taste - impact on food preferences and food production. Forum Nutr 2007;60:176-182.

Thorisson GA, Stein LD: The SNP Consortium website: past, present and future. Nucleic Acids Res 2003;31:124-127. Elliott RM: Transcriptomics and micronutrient research. Br J Nutr 2008;(suppl 3):S59-S65.

Scalbert A, Brennan L, Fiehn O, et al: Mass-spectrometry-based metabolomics: limitations and recommendations for future progress with particular focus on nutrition research. Metabolomics 2009;5:435-458.

El-Sohemy A: Nutrigenetics. Forum Nutr 2007;60:25-30.

Cornelis MC, El-Sohemy A, Kabagambe EK, Campos H: Coffee, CYP1A2 genotype, and risk of myocardial infarction. JAMA 2006;295:1135-1141.

Cornelis MC, El-Sohemy A: Coffee, caffeine, and coronary heart disease. Curr Opin Lipidol 2007;18:13-19.

Kaput J: Nutrigenomics - 2006 update. Clin Chem Lab Med 2007;45:279-287.

Levy S, Sutton G, Ng P, et al: The diploid genome sequence of an individual human. PLoS Biol 2007;5:e254.

United States Department of Agriculture: Steps to a healthier you. www.mypyramid.gov

Ferguson LR, Philpott M, Dryland P: Nutrigenomics in the whole-genome scanning era: Crohn's disease as example. Cell Mol Life Sci 2007;64:3105-3118.

Ng PC, Murray SS, Levy S, Venter JC: An agenda for personalized medicine. Nature 2009;461:724-726.

Lazarou J, Pomeranz BH, Corey PN: Incidence of adverse drug reactions in hospitalized patients: a meta-analysis of prospective studies. JAMA 1998;279:1200-1205.

Pirmohamed M, James S, Meakin S, et al: Adverse drug reactions as cause of admission to hospital: prospective analysis of 18820 patients. BMJ 2004;329:15-19.

Sangkuhl K, Berlin DS, Altman RB, Klein TE: PharmGKB: understanding the effects of individual genetic variants. Drug Metab Rev 2008;40:539-551.

McGough N, Cummings JH: Coeliac disease: a diverse clinical syndrome caused by intolerance of wheat, barley and rye. Proc Nutr Soc 2005;64:434-450.

Ciacci C, Iovino P, Amoruso D, Siniscalchi M, Tortora R, Di Gilio A, Fusco M, Mazzacca G: Grown-up coeliac children: the effects of only a few years on a gluten-free diet in childhood. Aliment Pharmacol Ther 2005;21:421-429.

Greco L, Romino R, Coto I, et al: The first large population based twin study of coeliac disease. Gut 2002;50:624-628. Romanos J, van Diemen CC, Nolte IM, et al: Analysis of HLA and non-HLA alleles can identify individuals at high risk for celiac disease. Gastroenterology 2009;137:834-840.

Arkadianos I, Valdes AM, Marinos E, Florou A, Gill RD, Grimaldi KA: Improved weight management using genetic information to personalize a calorie controlled diet. Nutr J 2007;6:29-35.

Tapueru-French CA: Can the use of genetics benefit weight loss in a New Zealand setting? Unpubl MSc thesis, University of Auckland, 2009.

Frayling TM, Timpson NJ, Weedon MN, Zeggini E, Freathy RM, Lindgren CM, Perry JR, Elliott KS, Lango H, et al: A common variant in the FTO gene is associated with body mass index and predisposes to childhood and adult obesity. Science 2007;316:889-894.

Andreasen CH, Stender-Petersen KL, Mogensen MS, et al: Low physical activity accentuates the effect of the FTO rs9939609 polymorphism on body fat accumulation. Diabetes 2007;57:95-101.

Adibhatla RM, Hatcher JF: Altered lipid metabolism in brain injury and disorders. Subcell Biochem 2008;49:241-268. Oster T, Pillot T: Docosahexaenoic acid and synaptic protection in Alzheimer's disease mice. Biochim Biophys Acta 2010;1801:791-798.

Suchy J, Chan A, Shea TB: Dietary supplementation with a combination of alpha-lipoic acid, acetyl-L-carnitine, glycerophosphocoline, docosahexaenoic acid, and phosphatidylserine reduces oxidative damage to murine brain and improves cognitive performance. Nutr Res 2009;29:70-74.

Zhao H, Li Q, Zhang Z, Pei X, Wang J, Li Y: Long-term ginsenoside consumption prevents memory loss in aged SAMP8 mice by decreasing oxidative stress and up-regulating the plasticity-related proteins in hippocampus. Brain Res 2009; 1256:111-122.

Vauzour D, Corona G, Spencer JP: Caffeic acid, tyrosol and p-coumaric acid are potent inhibitors of 5-S-cysteinyldopamine induced neurotoxicity. Arch Biochem Biophys 2010;501:106-111. 


\section{Nutrigenetics \\ Nutrigenomics}

\begin{tabular}{l|l}
\hline J Nutrigenet Nutrigenomics 2011;4:69-89 \\
\hline DOI: 10.1159/000327772 & ○ 2011 S. Karger AG, Basel \\
Published online: May 28, 2011 & \\
\hline
\end{tabular}

Fenech et al.: Viewpoints on the Current Status of Nutrigenetics and Nutrigenomics

-48 Chen CM, Yin MC, Hsu CC, Liu TC: Antioxidative and anti-inflammatory effects of four cysteine-containing agents in striatum of MPTP-treated mice. Nutrition 2007;23:589-597.

49 Bouwman LI: Personalized nutrition advice, an everyday-life perspective; thesis, Wageningen University, 2008, ISBN 978-90-8585-363-3.

50 Tai ES, Tan CE: Genes, diet and serum lipid concentrations: lessons from ethnically diverse populations and their relevance to coronary heart disease in Asia. Curr Opin Lipidol 2004;15:5-12.

51 Mak KH, Chia KS, Kark JD, et al: Ethnic differences in acute myocardial infarction in Singapore. Eur Heart J 2003; 24:151-160.

52 Tan CE, Emmanuel SC, Tan BY, Jacob E: Prevalence of diabetes and ethnic differences in cardiovascular risk factors. The 1992 Singapore National Health Survey. Diabetes Care 1999;22:241-247.

53 Cutter J, Tan BY, Chew SK: Levels of cardiovascular disease risk factors in Singapore following a national intervention programme. Bull World Health Organ 2001;79:908-915.

54 Hughes K: Trends in mortality from ischaemic heart disease in Singapore, 1959 to 1983. Int J Epidemiol 1986;15:44-50.

55 Khoo KL, Tan H, Liew YM, Deslypere JP, Janus E: Lipids and coronary heart disease in Asia. Atherosclerosis 2003; 169:1-10.

56 Dina C, Meyre D, Gallina S, et al: Variation in FTO contributes to childhood obesity and severe adult obesity. Nat Genet 2007;39:724-726.

57 Frayling TM, Timpson NJ, Weedon MN, et al: A common variant in the FTO gene is associated with body mass index and predisposes to childhood and adult obesity. Science 2007;316:889-894.

58 Cecil JE, Tavendale R, Watt P, Hetherington MM, Palmer CN: An obesity-associated FTO gene variant and increased energy intake in children. N Engl J Med 2008;359:2558-2566.

59 Rampersaud E, Mitchell BD, Pollin TI, et al: Physical activity and the association of common FTO gene variants with body mass index and obesity. Arch Intern Med 2008;168:1791-1797.

60 Vimaleswaran KS, Li S, Zhao JH, et al: Physical activity attenuates the body mass index-increasing influence of genetic variation in the FTO gene. Am J Clin Nutr 2009;90:425-428.

61 Reaven GM: The metabolic syndrome: requiescat in pace. Clin Chem 2005;51:931-938.

62 Abbasi F, Brown BW Jr, Lamendola C, McLaughlin T, Reaven GM: Relationship between obesity, insulin resistance, and coronary heart disease risk. J Am Coll Cardiol 2002;40:937-943.

63 Corella D, Qi L, Tai ES, et al: Perilipin gene variation determines higher susceptibility to insulin resistance in Asian women when consuming a high-saturated fat, low-carbohydrate diet. Diabetes Care 2006;29:1313-1319.

-64 Tai ES, Ordovas JM: The role of perilipin in human obesity and insulin resistance. Curr Opin Lipidol 2007;18:152-156.

65 World Cancer Research Fund, American Institute of Cancer Research, Diet, Nutrition and Prevention of Human Cancer: A Global Perspective, World Cancer Research Fund. Washington, American Institute of Cancer Research, 2007.

66 World Health Organization: The World Health Report, Reducing Risks, Promoting Healthy Life. Geneva, World Health Organization, 2002.

67 Doll R, Peto R: The causes of cancer: quantitative estimates of avoidable risks of cancer in the United States today. J Natl Cancer Inst 1981;66:1191-1308.

68 Enderlin CA, Coleman EA, Stewart CB, Hakkak R: Dietary soy intake and breast cancer risk. Oncol Nurs Forum 2009; 36:531-539.

69 Chen D, Dou QP: Tea polyphenols and their roles in cancer prevention and chemotherapy. Int J Mol Sci 2008;9:11961206.

70 Kavanaugh CJ, Trumbo PR, Ellwood KC: The U.S. Food and Drug Administration's evidence-based review for qualified health claims: tomatoes, lycopene, and cancer. J Natl Cancer Inst 2007;99:1074-1085.

71 Lampe JW: Interindividual differences in response to plant-based diets: implications for cancer risk. Am J Clin Nutr 2009;89:1553S-1557S.

72 Milner JA: Nutrition and cancer: essential elements for a roadmap. Cancer Lett 2008;269:189-198.

73 Davis CD, Milner JA: Biomarkers for diet and cancer prevention research: potentials and challenges. Acta Pharmacol Sin 2007;28:1262-1273.

74 Moy KA, Yuan JM, Chung FL, Wang XL, Van Den Berg D, Wang R, Gao YT, Yu MC: Isothiocyanates, glutathione Stransferase M1 and T1 polymorphisms and gastric cancer risk: a prospective study of men in Shanghai, China. Int J Cancer 2009; 125:2652-2659.

-75 Küry S, Buecher B, Robiou-du-Pont S, Scoul C, Sébille V, Colman H, Le Houérou C, Le Neel T, Bourdon J, Faroux R, Ollivry J, Lafraise B, Chupin LD, Bézieau S: Combinations of cytochrome P450 gene polymorphisms enhancing the risk for sporadic colorectal cancer related to red meat consumption. Cancer Epidemiol Biomarkers Prev 2007;16: $1460-1467$.

76 Jiang J, Gajalakshmi V, Wang J, Kuriki K, Suzuki S, Nakamura S, Akasaka S, Ishikawa H, Tokudome S: Influence of the C161T but not Pro12Ala polymorphism in the peroxisome proliferator-activated receptor-gamma on colorectal cancer in an Indian population. Cancer Sci 2005;96:507-512.

-77 Perry GH, Dominy NJ, Claw KG, Lee AS, Fiegler H, Redon R, Werner J, Villanea FA, Mountain JL, Misra R, Carter NP, Lee C, Stone AC: Diet and the evolution of human amylase gene copy number variation. Nat Genet 2007;39:12561260.

78 Johansson I, Ingelman-Sundberg M: CNVs of human genes and their implication in pharmacogenetics. Cytogenet Genome Res 2008;123:195-204. 


\section{Nutrigenetics \\ Nutrigenomics}

J Nutrigenet Nutrigenomics 2011;4:69-89

DOI: $10.1159 / 000327772$

Published online: May 28, 2011

2011 S. Karger AG, Base

Fenech et al.: Viewpoints on the Current Status of Nutrigenetics and Nutrigenomics

79 Stratigopoulos G, Padilla SL, LeDuc CA, Watson E, Hattersley AT, McCarthy MI, Zeltser LM, Chung WK, Leibel RL: Regulation of Fto/Ftm gene expression in mice and humans. Am J Physiol Regul Integr Comp Physiol 2008;294:R1185R1196.

80 Ferguson LR: Role of dietary mutagens in cancer and atherosclerosis. Curr Opin Clin Nutr Metab Care 2009;12:343349.

81 Abrams SA, Griffin IJ, Hawthorne KM, Chen Z, Gunn SK, Wilde M, Darlington G, Shypailo RJ, Ellis KJ: Vitamin D receptor Fok1 polymorphisms affect calcium absorption, kinetics, and bone mineralization rates during puberty. J Bone Miner Res 2005;20:945-953.

82 Wong HL, Seow A, Arakawa K, Lee HP, Yu MC, Ingles SA: Vitamin D receptor start codon polymorphism and colorectal cancer risk: effect modification by dietary calcium and fat in Singapore Chinese. Carcinogenesis 2003;24:1091-1095.

83 Ross SA: Nutritional genomic approaches to cancer prevention research. Exp Oncol 2007;29:250-256

84 Dolinoy DC: The agouti mouse model: an epigenetic biosensor for nutritional and environmental alterations on the fetal epigenome. Nutr Rev 2008;66:S7-S11.

85 Dolinoy DC, Weidman JR, Waterland RA, Jirtle RL: Maternal genistein alters coat color and protects Avy mouse offspring from obesity by modifying the fetal epigenome. Environ Health Perspect 2006;114:567-572.

86 Myzak MC, Dashwood RH: Histone deacetylases as targets for dietary cancer preventive agents: lessons learned with butyrate, diallyl disulfide, and sulforaphane. Curr Drug Targets 2006;7:443-452.

87 Myzak MC, Hardin K, Wang R, Dashwood RH, Ho E: Sulforaphane inhibits histone deacetylase activity in BPH-1, LnCaP and PC-3 prostate epithelial cells. Carcinogenesis 2006;27:811-819.

88 Lackner DH, Bähler J: Translational control of gene expression from transcripts to transcriptomes. Int Rev Cell Mol Biol 2008;271:199-251.

89 Goh KI, Cusick ME, Valle D, Childs B, Vidal M, Barabási AL: The human disease network. Proc Natl Acad Sci USA 2007; 104:8685-8690.

90 Legg RL, Tolman JR, Lovinger CT, Lephart ED, Setchell KD, Christensen MJ: Diets high in selenium and isoflavones decrease androgen-regulated gene expression in healthy rat dorsolateral prostate. Reprod Biol Endocrinol 2008;6:57.

91 Kim YS, Milner JA: Dietary modulation of colon cancer risk. J Nutr 2007;137:2576S-2579S

92 van Erk MJ, Blom WA, van Ommen B, Hendriks HF: High-protein and high-carbohydrate breakfasts differentially change the transcriptome of human blood cells. Am J Clin Nutr 2006;84:1233-1241.

$\checkmark 93$ Lin DW, Neuhouser ML, Schenk JM, Coleman IM, Hawley S, Gifford D, Hung H, Knudsen BS, Nelson PS, Kristal AR: Low-fat, low-glycemic load diet and gene expression in human prostate epithelium: a feasibility study of using cDNA microarrays to assess the response to dietary intervention in target tissues. Cancer Epidemiol Biomarkers Prev 2007; 16:2150-2154.

94 Trujillo E, Davis C, Milner J: Nutrigenomics, proteomics, metabolomics, and the practice of dietetics. J Am Diet Assoc 2006;106:403-413.

95 Zucker M: Studies into the relationship between GPCR43 and BuA-induced effects on colorectal cancer; thesis, University of Adelaide, 2008.

96 Fung KY, Lewanowitsch T, Henderson ST, Priebe I, Hoffmann P, McColl SR, Lockett T, Head R, Cosgrove LJ: Proteomic analysis of butyrate effects and loss of butyrate sensitivity in HT29 colorectal cancer cells. J Proteome Res 2009;8: $1220-1227$.

97 Topping DL, Clifton PM: Short-chain fatty acids and human colonic function: roles of resistant starch and nonstarch polysaccharides. Physiol Rev 2001;81:1031-1064.

98 Hamer HM, Jonkers D, Venema K, Vanhoutvin S, Troost FJ, Brummer RJ: Review article: the role of butyrate on colonic function. Aliment Pharmacol Ther 2008;27:104-119.

$\$ 99$ Fung KY, Lewanowitsch T, Henderson ST, Priebe I, Hoffmann P, McColl SR, Lockett T, Head R, Cosgrove LJ: Proteomic analysis of butyrate effects and loss of butyrate sensitivity in HT29 colorectal cancer cells. J Proteome Res 2009;8: $1220-1227$.

100 Ahmed K, Tunaru S, Offermanns S: GPR109A, GPR109B and GPR81, a family of hydroxy-carboxylic acid receptors. Trends Pharmacol Sci 2009;30:557-562.

101 Gupta N, Martin PM, Prasad PD, Ganapathy V: SLC5A8 (SMCT1)-mediated transport of butyrate forms the basis for the tumor suppressive function of the transporter. Life Sci 2006;78:2419-2425.

102 Mariadason JM, Corner GA, Augenlicht LH: Genetic reprogramming in pathways of colonic cell maturation induced by short chain fatty acids: comparison with trichostatin A, sulindac, and curcumin and implications for chemoprevention of colon cancer. Cancer Res 2000;60:4561-4572.

103 Cresci GA, Thangaraju M, Mellinger JD, Liu K, Ganapathy V: Colonic gene expression in conventional and germ-free mice with a focus on the butyrate receptor GPR109A and the butyrate transporter SLC5A8. J Gastrointest Surg 2010; 14:449-461.

104 Ganapathy V, Gopal E, Miyauchi S, Prasad PD: Biological functions of SLC5A8, a candidate tumour suppressor. Biochem Soc Trans 2005;33:237-240.

105 Sina C, Gavrilova O, Forster M, Till A, Derer S, Hildebrand F, Raabe B, Chalaris A, Scheller J, Rehmann A, Franke A, Ott S, Hasler R, Nikolaus S, Folsch UR, Rose-John S, Jiang HP, Li J, Schreiber S, Rosenstiel P: G protein-coupled receptor 43 is essential for neutrophil recruitment during intestinal inflammation. J Immunol 2009;183:7514-7522.

106 Thangaraju M, Cresci GA, Liu K, Ananth S, Gnanaprakasam JP, Browning DD, Mellinger JD, Smith SB, Digby GJ, Lambert NA, Prasad PD, Ganapathy V: GPR109A is a G-protein-coupled receptor for the bacterial fermentation product butyrate and functions as a tumor suppressor in colon. Cancer Res 2009;69:2826-2832. 


\section{Nutrigenetics \\ Nutrigenomics}

\begin{tabular}{l|l}
\hline J Nutrigenet Nutrigenomics 2011;4:69-89 \\
\hline $\begin{array}{l}\text { DOl: 10.1159/000327772 } \\
\text { Published online: May 28, 2011 }\end{array}$ & $\odot 2011$ S. Karger AG, Basel \\
\hline Fenech et al.: Viewpoints on the Current Status of Nutrigenetics and Nutrigenomics
\end{tabular}

107 Thangaraju M, Gopal E, Martin PM, Ananth S, Smith SB, Prasad PD, Sterneck E, Ganapathy V: SLC5A8 triggers tumor cell apoptosis through pyruvate-dependent inhibition of histone deacetylases. Cancer Res 2006;66:11560-11564.

108 Cahill LE, Fontaine-Bisson B, El-Sohemy A: Functional genetic variants of glutathione S-transferase protect against serum ascorbic acid deficiency. Am J Clin Nutr 2009;90:1411-1417.

109 Xie L, Innis SM: Genetic variants of the FADS1 FADS2 gene cluster are associated with altered (n-6) and (n-3) essential fatty acids in plasma and erythrocyte phospholipids in women during pregnancy and in breast milk during lactation. J Nutr 2008;138:2222-2228.

110 Yuan J-M, Koh W-P, Sun C-L, Lee H-P, Yu MC: Green tea intake, ACE gene polymorphism and breast cancer risk among Chinese women in Singapore. Carcinogenesis 2005;26:1389-1394.

-111 Petermann I, Triggs CM, Huebner C, et al: Mushroom intolerance: a novel diet-gene interaction in Crohn's disease. Br J Nutr 2009;102:506-508.

112 McBride CM, Koehly LM, Sanderson SC, Kaphingst KA: The behavioral response to personalized genetic information: will genetic risk profiles motivate individuals and families to choose more healthful behaviors? Annu Rev Public Health 2010;31:89-103. 